\title{
Review on Higher Diploma Training Experiences, Quality Teaching and Its Challenges in Mizan_Tepi University, Ethiopia
}

\author{
Miressa Yadessa \\ Mizan-Tepi University, Ethiopia
}

\begin{abstract}
The purpose of this review is to examine the existing practices of quality teaching in Mizan_Tepi University. Specifically, it is to discuss on how the knowledge, experiences and skills acquired from higher diploma program training is linked to quality teaching-learning. Higher diploma program training is effectively undertaking in Mizan_Tepi University. About 572 university academic staffs have been completed this training program within the last ten years. However, the impact of this training on the effective teaching of academic staff is not conducted yet. For this matter researches that have been done by different universities on this regard has been reviewed and compared with the real practices. Session observations of higher diploma trained academic staff classrooms, focus group discussion with the program candidates and teaching experiences were used as a base for this review. In general, the long period of time teaching experiences in the university and frequent session observations made indicates that the real practice of teaching and learning situation in Mizan_Tepi university looks like similar with the traditional teaching approach in which students are considered as passive listeners. Most teachers failed to make their lesson active and increase students' engagement by blaming the mismatch between the contents of the subject in terms of its scope and the modular teaching approach. In practice it is observed that instructors are unused this skills and experiences that they have gained from higher diploma training in spite of the real use of it to facilitate students' better learning. Some instructors with being less reflective of themselves, they attribute every failure to students though the program is supposed to help the realization of reflectiveness of teachers based on the constructivist teaching approach. Student engagement is most powerful in the process of quality teaching. To make such culture happen first teachers expected to believe that students learn better when they become active participant and create an environment which gives an opportunity to engage into learning. And also students must take responsibility for their learning and work hard to achieve the desired objectives. Lastly, the reviewer strongly recommends the academic community that to realize the usage of knowledge, skills and experiences gained from the training there has to be genuine focus, concern and commitment towards the quality teaching in the University.
\end{abstract}

Keywords: Higher Diploma Training Experiences, Quality of Teaching

DOI: $10.7176 / \mathrm{JEP} / 10-10-11$

Publication date: April $30^{\text {th }} 2019$

\section{Introduction}

Higher diploma training program is a one-year training designed for higher education institution academic staff. It is started in (2003) in Ethiopian as a new compulsory qualification for all academic staff. Mizan_Tepi University is formally started the training in the year (2008) with the support of volunteers from different countries. The program is centrally coordinated and facilitated by the Ministry of Education. The aim of the higher diploma training program is to improve the quality of education in Ethiopia through a licensing program that aims to develop the skills and professionalism of teachers, Higher Diploma Handbook (2011). Specifically, higher diploma training program enable teachers through supporting the implementation of the teachers teaching skills, identifying their own needs, demonstrating high standards of professional ethics, developing teaching skill based on sound theoretical knowledge and experience, exemplifying good practice and contributing to institutional and community development. The program also provides a high quality teaching experience for teachers and involves action research, collaborative learning, team work, gender issues and social inclusion. In the university there has been big achievements for the last ten years in terms of the qualities of the training and number of the graduates. Graph below shows the number of academic staff of the university who have been trained higher diploma training program over time 


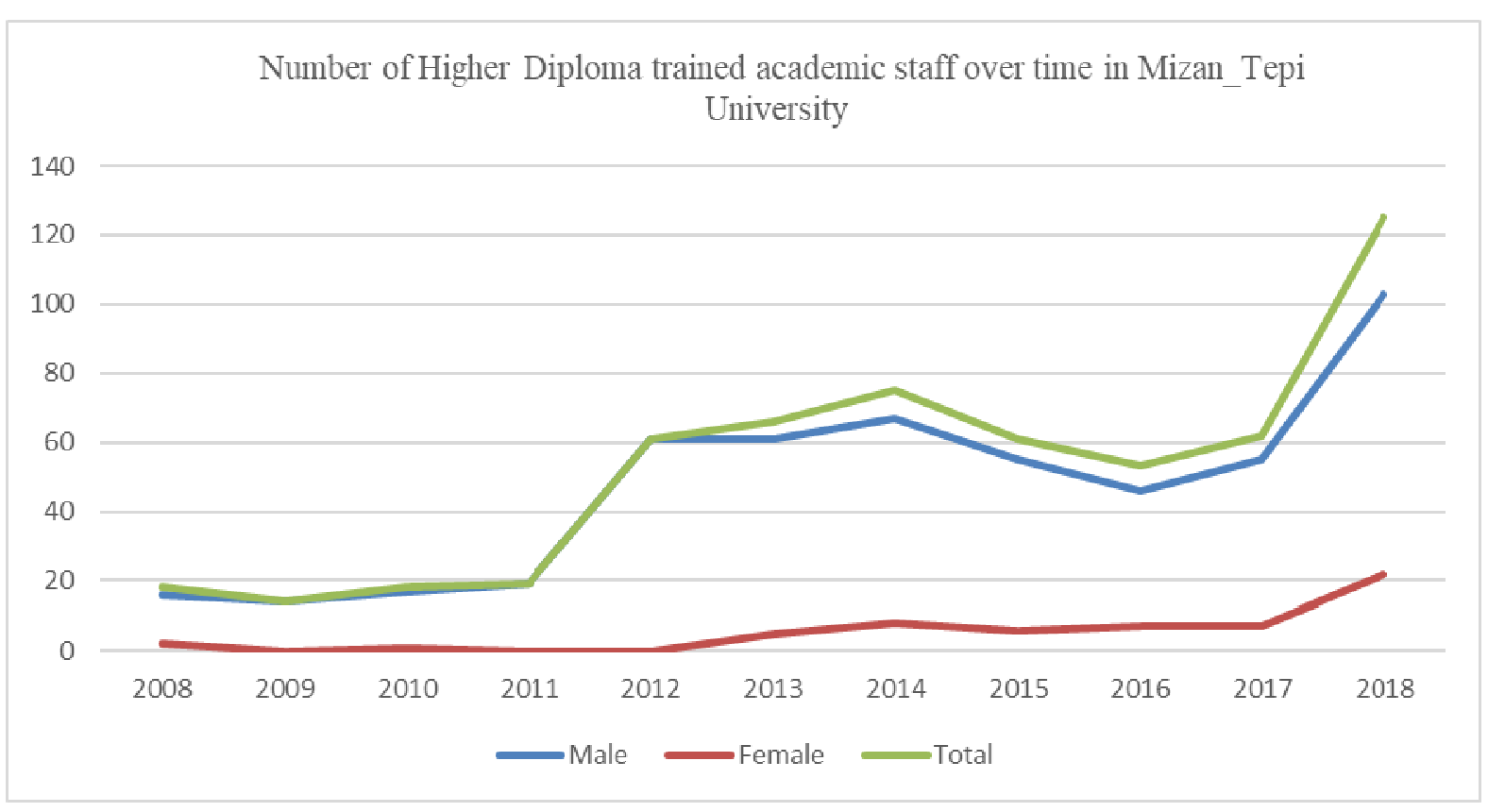

\section{Objectives of this review}

The purpose of this review is to examine the present practices of quality teaching in Mizan_Tepi University. Specifically, it aims to assess how the knowledge, experiences and skills acquired from higher diploma training program are linked to quality teaching-learning. It also aimed to identify the challenges encountered while using the expertise obtained from higher diploma training program in real classroom teaching. Finally, this review tried to examine the awareness and understandings of academic staff who have completed higher diploma training program and those who did not regarding their teaching quality and suggested the way forward to enhance quality teaching and learning in the university.

\section{Literature Review}

National experiences and studies show that offering higher diploma training program is an internal system of enhancing quality teaching and comprehensive measures of quality education covering professional development of academic staff. According to the Federal Republic of Ethiopian Ministry of Education directives it is assumed that higher diploma program is running successfully in almost all higher education institutions. Especially in the recent programs of professional development for higher education academic staff, higher diploma training program is considered as fundamental to enhance teaching skills. Besides, the Ministry is encouraging the Universities to conduct a study on its impacts on the teaching quality and effectiveness of teachers. Accordingly, the finding which was conducted at University of Gondar in Ethiopia on implementation of the expertise acquired from the training in comparison with non-trained staff in 2015 concluded that academic staff who have trained are found to be better at reflective practice than that of non-trained academic staff, implementing a variety of active learning and assessment techniques. Similarly, Aksum University of the same country has conducted a research on attitude and implementation barriers of higher diploma training program. The results reveals that the faculty's attitudes towards the training is positive but implementation barriers exist in the university. Asella College of Teacher Education in Ethiopia similarly conducted impact assessment to assess the effectiveness of the program and identified the continuous professional development needs of the academic staff, McEvoy P E. and Aga E (2009). This result summarized that the majority of academic staff believed that higher diploma training program has enhanced their professional development and hence the learning of the students. A study conducted at Jimma University in Ethiopia by Adula B (2008) on application of higher diploma training program skills in classroom instruction concluded that graduates are not applying the skills to the expected level. According to this finding, the factors for the failure of implementing higher diploma training program skills at classroom level are attributed not only to the physical constraints but also to the lack of interest from the academic staff and students and absence of well-organized follow-up that enforces or reinforces instructors to use the training skills. Haramaya University which has been running very successful Higher diploma training program over many years and is a moderating university developed its own manual on teaching methodology for all new teachers based on impact assessment study results to fill an identified skills gap and professional development need. The implication of the above finding is that though the aforementioned challenges are there for the implementation, the training enhances the teaching skills of teachers and learning interest of the students. 


\section{Teaching Practices, Theoretical Analysis and Implications}

Based on a long period of time teaching experiences and session observations it is fair to conclude that the real practice of teaching and learning situation in Mizan_Tepi university is similar to the traditional teaching approach in which students are considered as passive listeners. Similarly, a research finding done by Matheas $\mathrm{S}$ and Miressa Y, (2017) on Modular Teaching Approach at Mizan-Tepi University concludes that most teachers failed to use the knowledge, experience and skills need to make their lesson active and increase students' engagement by blaming the mismatch between the contents of the subject in terms of its scope and the modular teaching approach. However, many staff have taken higher diploma training program and pedagogical skill trainings designed to help teachers to shift their teaching approach from the traditional and teacher-centered approach to active teaching and learning approach at different times.

Traditional teaching approach is widely practiced in real classroom teaching. This approach is named traditional, because according to Pollard (2008), a theory of teaching and learning like behaviorism theory which is greatly influenced by Skinner, (1978) considers learners as having a passive role in the learning process. In this case a teacher is seen as the subject expert and is in control of the learning process. This kind of understanding directly influences the practices and roles to transmit knowledge and skills. Hence, students are considered as passive recipients and extrinsically motivated. This implies that learning occurs only when teaching happens and so teachers prefer to preach to their students. Information flows towards one direction from teacher to students. The implication is that this approach in turn leads students to become dependent in their future career, and lose confidence. The possibility to make students creative is minimal. However, scholars like Silberman, (1970) conclude that education is not the only way to prepare for later life, but an aspect of life itself.

\section{Teaching Challenges of Higher Diploma Trained Academic Staff}

Lesson gained from regular session observations and focus group discussions made with the academic staff of the university indicates that major challenges are easily observed. Instructors who have completed higher diploma training but are not using the knowledge and skills that they have acquired from the training. There is apparently lack of awareness about the linkage of those knowledge and skills gained from training to quality teaching and learning. In this case, according to McKinney, (1988) fairness, application, challenge, entertainment and service as main components of quality teaching. In addition, Steve Higgins and Robert Coe, (2014) state that quality teaching includes content knowledge, quality of instruction, classroom management, teachers' belief, professional behavior and teaching climate. In other case more than 572 academic staff have completed higher diploma training in the university. However, only very few of them are on duty. Many of them have left the university. Unless strategies are designed to retain the potential and more experienced academic staff, the university runs its activities with less experienced and fresh instructors. Moreover, it is not researched whether higher diploma training has played its part in improving the interaction among teachers and students.

\section{Discussion}

This review result indicates that higher diploma trained academic staff have many reasons for why they did not use the knowledge, experiences and skills gained from the training. These include students' poor English language proficiency for effective communication, poor academic backgrounds, and lack of willingness to do extra individual learning activities. The existing class size (large) is not suitable for student-centered teaching approach. This makes the application of active learning methods difficult and continuous assessment unsuccessful. On the contrary, the modern teaching approach like constructivism learning theory by Jean Piaget, (1972) suggests that people learn through interaction between experience and thinking. Piaget considered learning as interaction between people and their environment. He considers learner as an active and independent role and negotiates with the teacher who in turn becomes the manager of the learning environment rather than teaching. According to this approach, teacher's role is to give students the opportunity to construct their own knowledge and skills gradually through actively engaging in their learning. Learning happens through actively doing on varieties of activities and can be independent of teaching. This directly helps students to build selfconfidence, insightful understanding, anticipate motivation and have learning autonomy. Teachers are supposed to lead students towards this independent learning systematically by using the knowledge, experience and skills obtained from higher diploma training. Another constructivist learning theorist, Vygotsky (1994) believed that learning is a social process; he saw learners as active, social and socially motivated. This constructive theory implies that learners need to be proactive in how they learn, taking new information, and shaping it to their understanding, rather than just sitting still and passively absorbing information. In recent decades, this method of learning has gradually become more popular in the school system. Higher diploma program training is assumed to enable teachers to create teaching and learning environment to prepare learners for future life and derive from constructivist learning theory. 


\section{Conclusions}

The review experience tell us that when it comes to practical situations the acquired knowledge, experiences and skills from higher diploma training are not used because some instructors seem to lack interest in addition to the learning culture of students and physical constraints of teachers. Many graduates are observed to be far behind of all these things. Some instructors, being less reflective of themselves, attribute every failure to students. If students are to learn desired outcomes in a reasonably effective manner, then the teachers' main duty is to get students engaged in learning activities. However, most teachers are using lecture type of teaching which does not give students chance to actively engage in the process. It seems they fail to put it into practice in real teaching. In contrary, Ministry of Education and the University have given special attention to excel higher education teachers' teaching quality to its customers through offering higher diploma training. Conclusively, student engagement is most powerful in the process of quality teaching. The implication of this review is that the more instructors are intrinsically motivated the better they work to deliver effective and successful instruction and apply the skills and knowledge gained during higher diploma training. To make it happens it is recommended that teachers must believe that students learn better when they become active participant and students must be responsible for their learning and work hard to achieve the desired objectives.

\section{References}

Abdissa A (2017). The Role of Higher Diploma Program in Improving Trained Teachers' Classroom Teaching Methods: Jimma College of Teachers Education. Ethiopia

Adula B (2008). Application of Higher Diploma Program Knowledge and Skills. Jimma University, Ethiopia

Aklilu H and Stuart Ro.Monroe (2014). Attitudes and Implementation Barriers of Higher Diploma Program. Aksum University. Ethiopia

HDP Handbook (2008). Edition Federal Ministry of Education. Ethiopia.

Matheas S and Miressa Y (2017). Modular Teaching Approach in Under Graduate Program. Mizan_Tepi University. Ethiopia

McEvoy P E and Aga E The Effectiveness of the Higher Diploma Programme for Teacher Educators at Asella TEC, Asella, Ethiopia (2009)

McKinney, (1988). Teaching Sociology. Stanford University.

Piaget J (1970/1972). The Principles of Genetic Epistemology (W. Mays, Trans.). London: Routledge and Kegan Paul.

Pollard A (2008) Reflective Teaching, $3^{\text {rd }}$ edn. (London: Continuum International Publishing Group)

Silberman, Chareles E (1970) Crisis in the Class Room: New York; Random House Inc.

Skinner B F (1978). Reflections on Behaviorism and Society, Englewood Cliffs: Prentice Hall

Steve Higgins (2014), Developing Great Teaching. Lesson from the international revers to effective professional development. Durham University.

Tadesse W/Gebreal et al. (2015). Higher Diploma Program Implementation Assessment. University of Gondor.

Vygotsky L S (1994). The development of academic concepts in school aged children. In R. van der Veer and J Valsiner (Eds.). 